\title{
Therapeutic effects of a horse riding simulator in children with cerebral palsy
}

\author{
Maria Beatriz Silva Borges ${ }^{1}$, Maria José da Silva Werneck², \\ Maria de Lourdes da Silva², Lenora Gandolfi ${ }^{3}$ Riccardo Pratesi ${ }^{3}$
}

\begin{abstract}
Objective: To evaluate the efficacy of horse ridding simulator on the sitting postural control of children with spastic diplegia. Method: Forty children were randomly divided in a group using the simulator (RS) and a group performing conventional physical therapy (CT). FScan/Fmat equipment was used to register maximal displacement in anteroposterior (AP) and medio-lateral (ML) directions with children in sitting position. At the pre and post intervention stage both groups were classified according to the Gross Motor Function Classification System (GMFCS) and, after intervention, by the AUQEI questionnaire (Autoquestionnaire Qualité de vie Enfant Image). Results: Comparison between groups disclosed statistically significant pos-intervention improvement both in the AP $(p<0.0001)$ as in the ML $(p<0.0069)$ direction in the RS group. Conclusion: The horse ridding simulator produced significant improvement in the postural control of children in sitting position, additionally showing a higher motor functionality and a better acceptance of the therapeutic intervention.
\end{abstract}

Key words: cerebral palsy, spastic diplegia, postural balance, horseback riding therapy.

Efeitos terapêuticos de um simulador de equitação em crianças portadoras de paralisia cerebral

\section{RESUMO}

Objetivo: Avaliar os efeitos terapêuticos de um simulador de equitação no controle postural sentado de crianças portadoras de diplegia espástica. Método: Quarenta crianças foram aleatoriamente divididas em dois grupos: 20 utilizaram o simulador (GS) e 20 realizaram fisioterapia convencional (TC). Foi efetuado o registro dos deslocamentos máximos na direção ântero-posterior (AP) e médio-lateral (ML) com a criança sentada, utilizando-se o sistema FScan/Fmat. Antes e após intervenção as crianças foram classificadas pelo Gross Motor Function Classification System (GMFCS) e, após intervenção, pelo AUQEl (Autoquestionnaire Qualité de vie Enfant Image). Resultados: Melhora estatisticamente significativa dos deslocamentos máximos foi observada após intervenção tanto na direção $\mathrm{AP}(p<0,0001)$ quanto na $\mathrm{ML}(\mathrm{p}<0,0069)$ no grupo GS quando comparado ao grupo TC. Conclusão: $O$ simulador de equitação produziu melhora significativamente maior no controle postural da criança sentada, aliada a maior funcionalidade motora e melhor aceitação da intervenção terapêutica.

Palavras-Chave: paralisia cerebral, diplegia espástica, equilíbrio postural, equitação terapêutica.

Correspondence

Maria Beatriz Silva e Borges Universidade Católica de Brasília Campus I - Q.S. 07 lote 01 EPCT 71966-700 Taguatinga DF - Brasil E-mail: mbeatrizborges@gmail.com

Received 23 August 2010 Received in final form 5 May 2011 Accepted 12 May 2011
The ability to maintain postural control is an important factor in performing daily activities and reaching an independent individual development ${ }^{1}$. Although Brasília School of Medicine, Brasília DF, Brazil. 
stable control of posture and balance is automatic for healthy individuals, this is often a challenge for patients with cerebral palsy $(\mathrm{CP})^{2}$.

The presence of spasticity, muscle weakness, musculoskeletal alterations and decreased pelvic movement common to children with $\mathrm{CP}$, make the sitting postural control worse than in healthy children ${ }^{1,3,4}$.

To maintain the sitting posture, children with $\mathrm{CP}$ perform stereotyped activation of extensor muscles, abnormal muscle recruitment and excessive activation of antagonist muscles ${ }^{5,6}$. This interferes with the quality of the reaching movement that basically depends on the postural control ${ }^{1}$. When the child sits with satisfatory postural control and good alignment, he will improve the functionality of his upper limbs for the actions of handling, eating and writing ${ }^{7,8}$. Different therapies have been described to improve the sitting postural control ${ }^{9}$.

Horseback riding therapy is a form of treatment that provides better movement of pelvis and hip, trunk, head and balance in response to the horse movements ${ }^{10,11}$. A study comparing horseback riding and Bobath method showed significant improvement in the group of children undergoing horseback riding therapy ${ }^{12}$. However, this modality of therapy is not easily available to the majority of CP children mostly due, among other factors, to the generally difficult access to horses and the high cost of the treatment ${ }^{13}$.

The Joba ${ }^{\circ}$ device (Matsushita Electric Works, ltd., Japan) was developed as an attempt to imitate the passive movement consequent to horse riding, with the advantage of providing a horse riding system that could be used indoors. The Joba ${ }^{\circ}$ produces simple movements which lead the child to experiencing the feelings of real horse riding. The improvement of muscular power and muscular strengthening are attainable only by the action of sitting down and keeping the balance.

The objective of the present study was to evaluate the potentially beneficial effects of the equipment in the sitting postural control of children with cerebral palsy spastic diplegia, proposing an innovative therapeutic intervention in order to provide to these children an alternative form of active treatment for trunk control, that is so important for their daily activities such as eating, writing, reaching and handling.

\section{METHOD}

A randomized clinical trial was conducted between February and December 2008 at the Clinic of Physiotherapy and Laboratory of Biomechanics of the Catholic University of Brasília (UCB). The experimental protocol was approved by the University Ethics Research Committee under the protocol n ${ }^{\circ} 57 / 06$.

The study included 40 children with CP spastic di- plegia randomly divided in two groups: the riding simulator (RS) group that included 20 children (eight boys and 12 girls; age range: 3 to 12 years; mean age: $5.65 \pm 2.48$ years; median age: 5 years) and the conventional physical therapy (CT) group composed of 20 children (nine boys and 11 girls; age range: 3 to 10 years; mean age: $5.77 \pm 2.29$ years; median age: 5 years). All parents or guardians were informed about the objective and methods of the study, including risks and benefits, and signed a written consent. Children who could not understand or refused to follow the study protocol, or disclosed deformities of the hip and/or spine, or those who had underwent surgery or received application of medication to reduce spasticity during the last six months were excluded from the study.

All children had their postural control evaluated by the record of their body oscillations before and after the period of intervention. The evaluation of the anteriorposterior (AP) and medial-lateral (ML) body oscillations was performed by recording the maximal displacement of the pressure center according to the protocol used by Lacoste ${ }^{14}$ in the F-Scan system (software version 4.21) and F-Mat sensor platform-type (model 3100, Tekscan, Inc., South Boston, MA). The system was calibrated before each recording following the manufacturer instructions. The platform was placed on a bench to accommodate the seated child and wooden blocks were used to support the child's feet to keep him in a comfortable position maintaining his hips and knees in a $90^{\circ}$ flexion.

Each data collection lasted one minute with a sampling frequency of $100 \mathrm{~Hz}$ while the child, sitting on the platform, was oriented to cross his arms as if to embrace his own body and to move his body forward and backward, and from left to right. No intervention was performed by the therapist during the test. Three data collections were performed in each child to obtain a final average value.

The data obtained by the F-Scan system were filtered by fourth-order Butterworth digital filter with cutoff frequency of $5 \mathrm{~Hz}$, using Labview software version 5.0 and were exported to an Excel spreadsheet. These assessments were blinded and performed by the technician of Biomechanics Laboratory of the institution.

The Gross Motor Function Classification System $(\text { GMFCS })^{15}$ was also applied to both groups. The GMFCS is a quick and easy to use, valid and reliable 5-level classification system based on self-initiated movement with particular emphasis on truncal control in the sitting position and in walking.

At the end of the study, all children were evaluated by the AUQEI scale (Autoquestionnaire Qualité de Vie Enfant image), that is a questionnaire for the assessment of the quality of life capable of evaluating the child's subjective well-being ${ }^{16}$. This questionnaire was validated in 


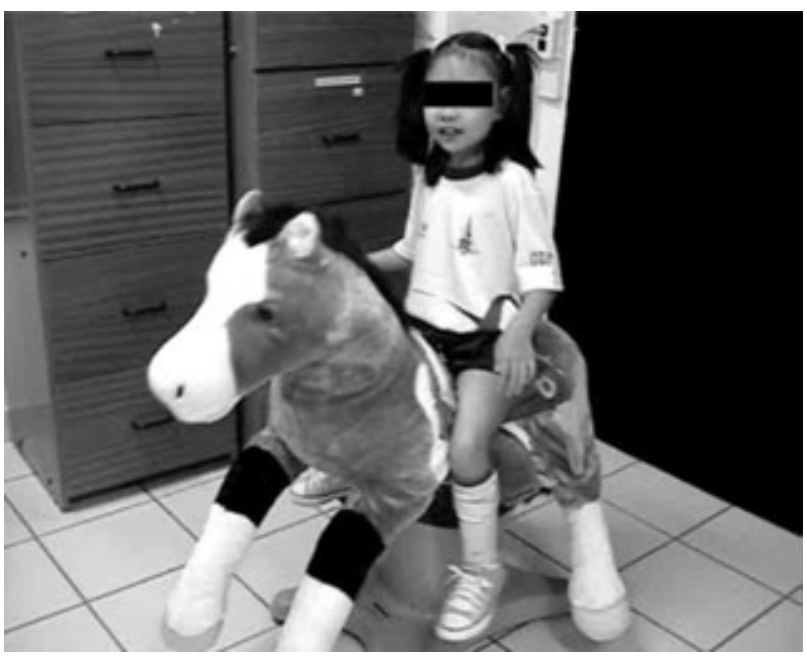

Fig 1. The riding simulator (Joba ${ }^{\circledR}$ ) disguised as a velvet pony.

Brazil by Assumpção Jr. et al. ${ }^{17}$ and by Christofoletti et al. ${ }^{18}$ that broadened the scope of questionnaire adding 14 more questions covering aspects of the motor disability and rehabilitation process. In the present study was used the original scale with the addition of only one the question of Christofoletti's modified scale. All children pertaining to the RS group underwent 12 treatment sessions administered in a two weekly basis, with 40 minutes of duration each, on the horseback riding simulator (Model EU6310) using the level 1 of the equipment and frequency of $100 \mathrm{~Hz}$, as previously performed by Kubota et al. ${ }^{19}$.

As can be seen in Fig 1, the horse riding simulator was covered by a plush pony, thus making the equipment more attractive and enjoyable for the children

The CT group underwent 12 sessions of conventional physical therapy based on the NeuroDevelopmental Treatment (NDT) with emphasis on specific techniques for trunk control, with two weekly sessions of 40 minutes each. All children were treated by the same experienced physical therapist, certified in NDT.

Statistical analysis of maximum displacement in AP and ML used a model of analysis of parametric covariance (ANCOVA), which aims to test whether there is significant difference between the two groups, taking into account the measurements obtained before the intervention. All the parametric ANCOVA assumptions were tested and showed satisfactory correlation between them: errors were independently and normally distributed, the population within-groups regression coefficients were equal, and linear relationship was present between pretest and posttest ${ }^{20}$.

A proportional odds model with generalized estimating equations $(\mathrm{GEE})^{21}$ was used for the variable GMFCS. To compare the degree of satisfaction between the two groups assessed by the AUQEI questionnaire

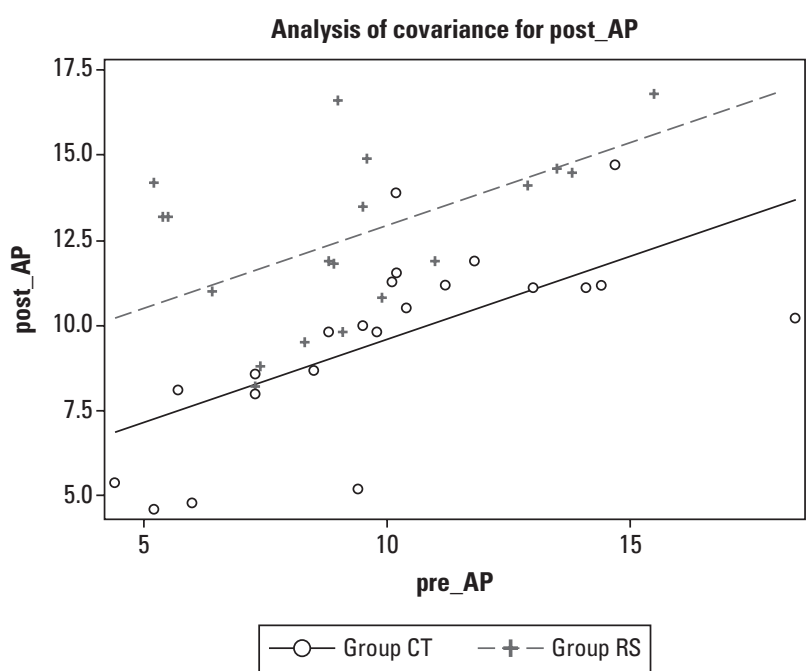

Fig 2. Analysis of covariance of the individual body oscillations in the AP direction, in the pre and posttest stages, assessed measuring the maximal displacement of the pressure center (F-Scan/ F-Mat system) in the two groups of children (RS and CT).

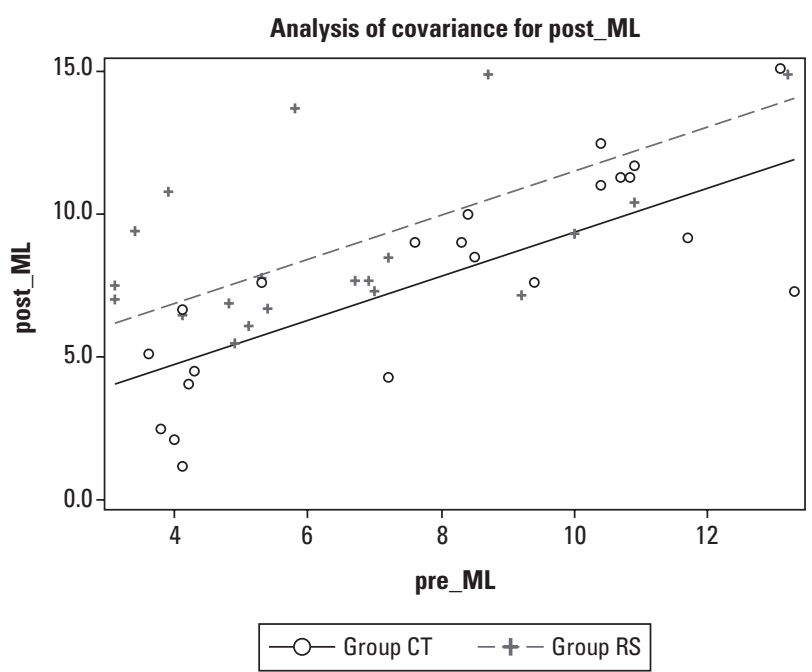

Fig 3. Analysis of covariance of the individual body oscillations in the $\mathrm{ML}$ direction, in the pre and posttest stages, assessed measuring the maximal displacement of the pressure center (F-Scan/ F-Mat system) in the two groups of children (RS and CT).

was used the chi-square Mantel-Haenszel test. For the purpose of analysis was used a significance level of 5\%.

\section{RESULTS}

The analysis of the parametric covariance of the displacement of the pressure center in the antero-posterior and medio-lateral directions, in children of both groups (RS and CT) in the pre and post-treatment stage can be seen in Fig 2 and Fig 3.

As can be seen, the individual variations in pre and post-test, both displacement in AP and ML were higher 
LS-Means for group

A

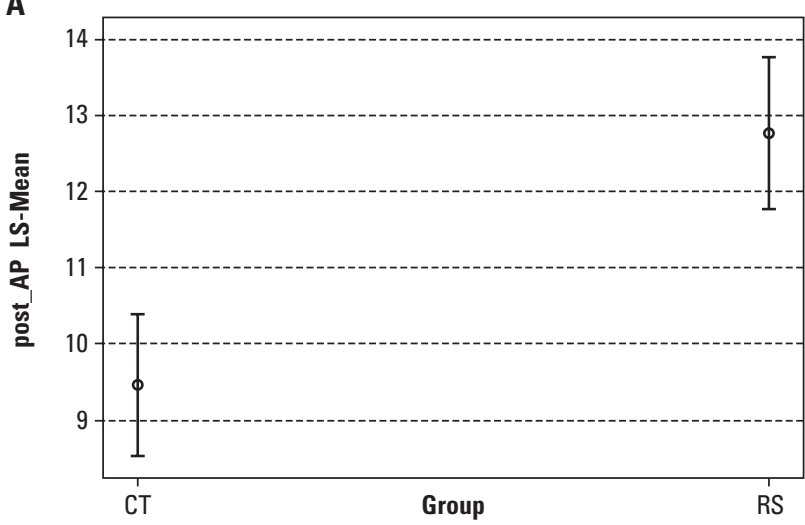

LS-Means for group with $95 \%$ confidence limits

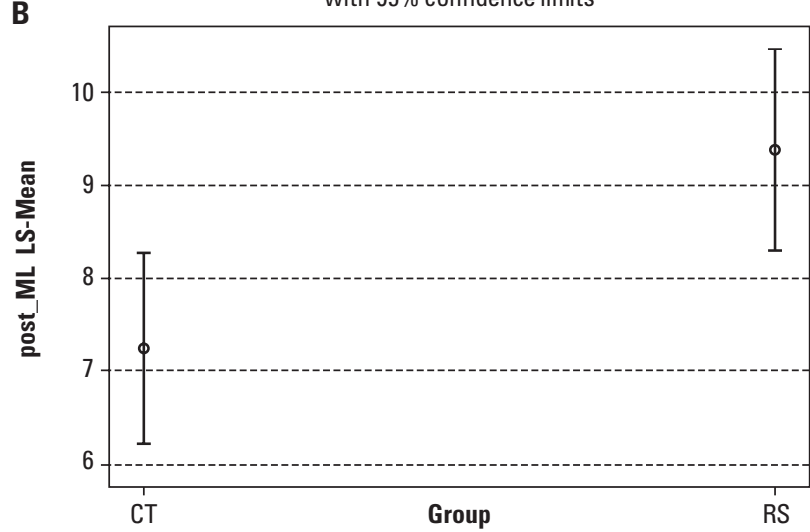

Fig 4. Comparison between the average of the individual measures of the maximal displacement in the $A P[A]$ and $M L[B]$ directions of both groups (RS and $\mathrm{CT}$ ) in the pre and posttest stage.

Table. Acquisitions pre and post intervention. Pre-intervention classification and pos-intervention acquisitions of two CT children (number 6 and 7) and five RS children (number 1, 2, 3, 4 and 5) that changed level on the GMFCS after the therapeutic intervention.

\begin{tabular}{|c|c|c|c|}
\hline Children & Age & Pre intervention & Post intervention \\
\hline 1 & 5 years & $\begin{array}{l}\text { Level III: He needed pelvic support to sit down and } \\
\text { to release his hands, and used a walker for short } \\
\text { distances }\end{array}$ & $\begin{array}{l}\text { Level II: He began to sit with his hands free, moving } \\
\text { from sitting to standing position using his arms; was } \\
\text { able to walk with the help of a walker around the } \\
\text { house and yard }\end{array}$ \\
\hline 2 & 5 years & $\begin{array}{l}\text { Level V: He was unable to sit down and was totally } \\
\text { dependent for his locomotion }\end{array}$ & $\begin{array}{l}\text { Level IV: He began to sit without support and was } \\
\text { able to move around using a walker with some } \\
\text { adjustments }\end{array}$ \\
\hline 3 & 8 years & $\begin{array}{l}\text { Level IV: He walked with the help of a walker for } \\
\text { short distances having difficulties in making turns } \\
\text { and with obstacles }\end{array}$ & $\begin{array}{l}\text { Level III: Started to use Canadian crutches and } \\
\text { improved the functionality of his upper limbs and } \\
\text { hand being able to manipulate objects and writing }\end{array}$ \\
\hline 4 & 7 years & Level III: Walked with the help of Canadians crutches & $\begin{array}{l}\text { Level II: Started independent gait training and was } \\
\text { able to walk without help for short distances }\end{array}$ \\
\hline 5 & 9 years & $\begin{array}{l}\text { Level V: He needed the help of adaptations to be } \\
\text { able to sit down sit }\end{array}$ & $\begin{array}{l}\text { Level IV: He was able to sit independently and started } \\
\text { using the walker with adaptations }\end{array}$ \\
\hline 6 & 10 years & $\begin{array}{l}\text { Level IV: He walked with the help of a walker for } \\
\text { short distances having difficulties in making turns } \\
\text { and with obstacles }\end{array}$ & $\begin{array}{l}\text { Level III: He was able to walk using Canadian } \\
\text { crutches for short distances and learned to propel his } \\
\text { wheelchair without help for longer distances }\end{array}$ \\
\hline 7 & 6 years & Level III: Walked with the help of Canadians crutches & $\begin{array}{l}\text { Level II: Started independent gait training and was } \\
\text { able to walk without help for short distances }\end{array}$ \\
\hline
\end{tabular}

CT: conventional physical therapy; RS: riding simulator; GMFCS: gross motor function classification system.

in the group using the simulator when compared to the conventional group.

In Fig 4 can be seen that, taking into account the individual measures obtained in the AP displacement in the pretest in both groups, the average of the post-test results of the RS group was statistically higher than the average obtained by the CT group $(\mathrm{p}<0.0001)$. The same results were observed in the ML displacement where the average of the individual post-test measures in the RS group was statistically higher than the average of the CT group ( $\mathrm{p}=0.0069)$.

The GMFCS was initially used as a classification system for children before the intervention. Eight children were classified as level II, 16 as level III, 14 as level 
IV and 2 as level V. However, in the end of the study, seven children were classified into different levels than previous. The children were evaluated again by another researcher who obtained the same result. Five children from RS and two children from CT obtained different functional levels before and after intervention, as shown in Table. Although the level change is not statistically significant, the children treated with a horse ridding simulator had 1.63 times more chances to show a better score after the treatment than before the treatment $(\mathrm{p}=0.0110)$. Similarly, the children treated by conventional therapy had 1.22 times more chances to obtain a better score after treatment than before the treatment $(\mathrm{p}=0.1510)$.

The scale AUQEI showed that with reference to general themes such as birthdays, holidays, socialization with family members and sports, the level of happiness was satisfactory in both groups. However, when specifically focusing on the physical therapy practice was observed that the group RS had more satisfactory results when compared to the $\mathrm{CT}$ group $(\mathrm{p}=0.0026)$ : no child was unhappy with the use of the simulator while $25 \%$ of children belonging to the $\mathrm{CT}$ group were unhappy with the therapy.

\section{DISCUSSION}

The sitting posture control is very important to improve the quality of life of children with $\mathrm{PC}$ and it has been for a long time one of the most important topic of study. In the 90's, Mechanical Artificial Saddles (BABS) came to be used with success in children treating with PC, resulting decreased spasticity, increased sitting stability, improvement in postural adjustments in unstable situations and quickly muscle recruiting ${ }^{8,13}$. However its use was gradually discontinued mainly because it was heavy, impractical and unattractive to the children. Traditionally, the physical therapy in the pediatric clinic is based on the neuroevolutive method, which aims to the inhibition of pathological reflexes, facilitating the appearance of new functional acquisitions. However, the success of this method in achieving better postural control has been questioned ${ }^{8,9}$. Despite of the traditional use in several countries during the last 60 years, it is a repetitive method that precociously became boring and discouraging for the children and their parents. Without abandoning the traditional methods it is important to introduce new technological innovations of proven effectiveness, which would provide a more dynamic approach to protocols of physical activity. The combination of an attractive therapy that provide good functional results and is concomitantly well accepted by the children will ensure their spontaneous and enjoyable participation ${ }^{9,20-22}$.

The Joba ${ }^{\circ}$ Riding Simulator has been used in programs of muscle strengthening with elderly people, showing increased muscular strength and contraction ${ }^{19,23-25}$. Their use was described in children, but its results have not been assessed ${ }^{26}$. To faithfully reproduce the movements of a horse, the physiological effects of the simulator are basically the same as the riding, without its disadvantages. It promotes, through movement, postural adjustments that activate specific muscle groups to maintain posture against gravity. The repetition of these adjustments cause, therefore, mainly muscle strengthening of pelvic, abdominal and lumbar muscles, causing improvement of the trunk balance and postural control against gravity $19,23,24,27,28$.

In Brazil, there are several hippotherapy centers that offer treatment to children with $\mathrm{PC}$, however there are several factors that complicate or even hinder its practice as adverse weather conditions, difficult access to riding centers often located in remote areas, the need to use properly trained animals, the often excessive cost of the therapeutic sessions due to the high expenses with the horses care, the frequent rejection of the therapy by the children for fear of the horse, the possibility of allergic reactions due to environmental antigens and finally, the difficulty in maintaining the treatment for long periods and to assess its possible results.

The riding simulator is a form of physical therapy that, besides being extremely motivating for children also has several advantages when compared to hippotherapy: it can be used in any place, as an office or a clinic, or even in the patient's own home, it is independent from weather conditions, and is relatively small and quiet. Additionally, is easy to handle and can be programmed for predetermined periods of time with the type of movements to be performed and the level of difficulty, which can be increased gradually and finally, children totally accept and enjoy this kind of therapy.

In this study, the evaluation of the effects of the riding simulator on the postural control of children with $\mathrm{CP}$ in sitting position disclosed a statistically significant improvement in the maximal displacement in the anteroposterior and medio lateral directions in the treated group (RS) when compared to the control group (CT). In association whit this enhancement of the postural control it was perceived by the parents a significant improvement of the child performance on daily activities that required greater mobility and postural control, associated with an increased mobility of the pelvis and improvement of the feeding process and sleeping pattern.

When children with PC sit in a good alignment they improve the upper limbs function ${ }^{1,5,6,8}$ with consequently positive results in school performance and increased satisfaction in daily activities. In the present study, the gains were evident not only by the better sitting postural control, but also by the change in the level of the GMFCS 
which is generally cited by the authors of the scale as extremely difficult to be obtained due to the fact that it is not a measuring scale of functional level. There are better instruments to measure the functional gains such as, for example, the $\mathrm{GMFM}^{29}$. In the present study, the GMFCS was used to classify children and not to assess their functional gains and the fact that five children of the RS and two of the CT showed gains beyond the postural control system measured by Fscan was a positive surprise. Apart from the gains in postural control in sitting position to get extra improvement obtaining a greater independence in their daily activities is important and stimulating for the patients, their families and for the therapist.

Determination, enthusiasm and joy are essential in working with children with $\mathrm{PC}^{12}$. The use of the riding simulator is a pleasant and daring activity for the child, a fact which ensures his interest and persistence in the therapy. The assessment of the quality life, by the AUQEI scale showed that the children undergoing the therapy with the riding simulator were happier with the therapeutic process when compared to children on conventional therapy, indubitably due to the entertaining and extremely dynamic components provided by the riding simulator.

In conclusion, the use of the horse ridding simulator was statistically superior when compared to the conventional physical therapy treatment both in the postural control in sitting position, as in the global functionality and satisfaction of the children and their families with physical therapy procedures.

\section{REFERENCES}

1. Van der Heide JC, Fock JM, Otten B, Stremmelaar E, Hadders-Algra M. Kinematic characteristics of postural control during reaching in preterm children with cerebral palsy. Pediatr Res 2005;58:586-593.

2. Ferdjallah M, Harris GF, Smith P, Wertsch JJ.Analysis of postural control synergies during quiet standing in healthy children and children with cerebral palsy. Clin Biomech 2002;17:203-210.

3. Woollacott MH, Burtner P, Jensen J, Jasiewicz J, Roncesvalles N, Sveistrup $H$. Development of postural responses during standing in healthy children and in children with spastic diplegia. Neurosci Biobehav Rev 1998; 22:583-589.

4. Quint C, Toomey M. Powered saddle and pelvic mobility. Physiotherapy 1998;84:376-384.

5. Brogren $\mathrm{E}$, Hadders-Algra M, Forssberg H. Postural control in sitting children with cerebral palsy. Neurosci Biobehav Rev 1998;22:591-596.

6. Liao SF, Yang TF, Hsu TC, Chan RC, Wei TS. Differences in seated postural control in children with spastic cerebral palsy and children who are typically developing. Am J Phys Med Rehabil 2003;82:622-626.

7. Redstone F, West JF. The importance of postural control for feeding Pediatric Nursing 2004;30:97-100.

8. Graaf Peters VB, Blauw-Hospers CH, Dirks T, Bakker H, Bos AF, HaddersAlgra M. Development of postural control in typically developing children and children with cerebral palsy: possibilities for intervention? Neurosci Biobehav Rev 2007;31:1191-1200.

9. Harris SR, Roxborough L. Efficacy and effetiveness of physical therapy in enhancing postural control in children with cerebral palsy. Neural Plasticity 2005; 12:2-3.

10. Sterba JA, Rogers BT, France AP, Vokes DA. Horseback rinding in children with cerebral palsy: effect on gross motor function. Dev Med Child Neurol 2002;44:301-308.

11. McGee M, Reese NB. Immediate effects of a hippotherapy session on gait parameters in children with spastic cerebral palsy. Pediatr Phys Ther 2009; 21:212-218.

12. Ionatamishvili NI, Tsverava DM, Loriya MS, Sheshaberidze EG, Rukhadze MM. Riding Therapy as a method of rehabilitation of children with cerebral palsy. Hum Physiol 2004;30:561-565.

13. Kuczyñski M, Slonka K. Influence of artificial saddle riding on postural stability in children with cerebral palsy. Gait Posture 1999;10:154-160.

14. Lacoste M, Therrien M, Côte JN, Shrier I, Labelle H, Prince F. Assessment of seated postural control in children: comparison of a force platform versus a pressure mapping system. Arch Phys Rehabil 2006;87:1623-1629.

15. Palisano R, Hanna SE, Rosenbaum PL, et al. Validation of a model of gross motor function for children with cerebral palsy. Phys Ther 2000;80: 974-985.

16. Manificat S, Guillaud-Bataille JM, Dazord A. La qualité de vie chez l'enfant atteint de maladie chronique.Revue de la littératuret aspects conceptuels. Pédiatrie 1993;7:519-527.

17. Assumpção Jr. FB, Kuczynski E, Sprovieri MH, Aranha EMG. Escala de Avaliação de Qualidade de vida (AUQEI Autoquestionnaire Qualité de Vie Enfant Imagé). Arq Neuropsiquiatr 2000;58:1-11.

18. Christofoletti G, Hygashi F, Godoy A. Paralisia cerebral: uma análise do comprometimento motor sobre a qualidade de vida. Fisioter Mov 2007; 20:37-44.

19. Kubota M, Nagasaqui M, Tokudome M, Shinomiya Y, Osawa T, Sato Y. Mechanical horseback riding improves insulin sensitivity in elder diabetic patients. Diab Res Clin Pract 2006;71:124-130.

20. Bonate PL. Analysis of pretest-posttest designs;Chapman and Hall CRC. Boca Raton FL USA, 2000.

21. Miller M E, Davis C S, Landis JR. The analysis of longitudinal polytomous data: generalized estimating equations and connections with weighted least squares. Biometrics1993;49:1033-1044.

22. Damiano LD. Activity, activity, activity: rethinking our physical therapy approach to cerebral palsy. Phys Ther 2006;86:1534-1540.

23. Shinomiya Y, Osawa T, Hosaka Y, Shuoyo Wang, Ishida K, Kimura T. Development and physical training evaluation of horseback riding therapeutic equipment. International Conference on advanced intelligent mechatronics, 2003:1239-1243.

24. Shinomiya Y, Nomura J, Yoshida Y, Kimura T. Horseback riding therapy simulator with VR technology. ACM Symposium on virtual Reality Software an Technology, 1997;9-14.

25. Mitani Y, Doi K, Ano T, Sakamaki E, Mukai K, Shinomiya Y, Kimura T. Effect of exercise using a horse-riding simulator on physical ability of frail seniors. J PhysTher Sci 2008;20:177-183.

26. Herrero P, Asensio A, Garcia E, Marco A, Olivan B, Ibarz A. Study of the therapeutic effects of an advanced hippotherapy simulator in children with cerebral palsy: a randomized controlled trial. BMC Musculoskelet Disord 2010;11:71

27. Kitagawa T, Takeuchi T, Shinomiya Y, Ishida K, Shuoyu W, Kimura T. Cause of active motor function by passive movement. J Phys Ther Sci 2001; 13:167-172.

28. Chung J, Evans J, Lee C, et al. Effectiveness of adaptive seating on sitting posture and postural control in children with cerebral palsy. Pediatr Phys Ther 2008;20:303-317.

29. Russell D, Rosenbaum P, Grewland C, et al. Administration and Scoring. In: Gross Motor Function Mesure Manual. McMaster University. Second Edition. Toronto, September, 1993. 